\title{
Why Are Narcissists so Charming at First Sight? Decoding the Narcissism-Popularity Link at Zero Acquaintance
}

\author{
Mitja D. Back \\ Johannes Gutenberg-University Mainz
}

\author{
Stefan C. Schmukle \\ Westfälische Wilhelms-University Münster
}

\author{
Boris Egloff \\ Johannes Gutenberg-University Mainz
}

\begin{abstract}
On the basis of a realistic behavioral approach, the authors showed that narcissists are popular at zero acquaintance and aimed to explain why this is the case. In Study 1, a group of psychology freshmen $(N=$ 73) judged each other on the basis of brief self-introductions using a large round-robin design $(2,628$ dyads). Three main findings were revealed: First, narcissism leads to popularity at first sight. Second, the aspects of narcissism that are most maladaptive in the long run (exploitativeness/entitlement) proved to be most attractive at zero acquaintance. Third, an examination of observable verbal and nonverbal behaviors as well as aspects of physical appearance provided an explanation for why narcissists are more popular at first sight. Results were confirmed using judgments of uninvolved perceivers under 3 different conditions for which the amount of available information was varied systematically: (a) full information (video and sound, Study 2), (b) nonverbal information only (video only, Study 3), or (c) physical information only (still photograph of clothing, Study 4). These findings have important implications for understanding the inter- and intrapersonal dynamics of narcissism.
\end{abstract}

Keywords: narcissism, interpersonal attraction, popularity, zero acquaintance, lens model

Legions of lusty men and bevies of girls desired him.—Ovid, 2004, Book III, Narcissus and Echo, line 353

Narcissism is conceptualized as a dysfunctional form of overly high self-esteem and a grandiose view of the self that is associated with a number of intra- and interpersonal problems (Morf \& Rhodewalt, 2001). While narcissists love the picture they have of themselves, for most people, narcissists are annoying and dislikable because they behave in a manner that is rather selfish, overly dominant, hostile, and arrogant (e.g., Colvin, Block, \& Funder, 1995; Morf \& Rhodewalt, 2001; Paulhus, 1998).

Things should, however, be different when first meeting a narcissist. We postulate that narcissists are more popular at first sight than nonnarcissists. In sources even outside of Greek mythology, narcissists are often described as possessing an immediately perceived charming and charismatic air (Morf \& Rhodewalt,

Mitja D. Back and Boris Egloff, Department of Psychology, Johannes Gutenberg-University Mainz, Germany; Stefan C. Schmukle, Department of Psychology, Westfälische Wilhelms-University Münster, Germany.

This research was supported by German Research Foundation (DFG) Grant BA 3731/1-1 awarded to Mitja D. Back. We thank Anastasia Bröske, Sarah Dudenhöffer, Sascha Haun, Sarah Hirschmüller, Joachim Marschall, Anna Pohl, Tina Seidel, and Juliane Stopfer for their help with data collection and Sarah Hirschmüller, Albrecht Küfner, Steffen Nestler, and Juliane Stopfer for inspiring discussions on this research and comments on an earlier version of this manuscript.

Correspondence concerning this article should be addressed to Mitja D. Back, Department of Psychology, Johannes Gutenberg-University Mainz, 55099 Mainz, Germany. E-mail: back@uni-mainz.de
2001; Young \& Pinsky, 2006). These anecdotal descriptions suggest that the narcissist's striving for admiration turns us off in the long run but fascinates us at first sight. Their manipulation tendencies might be ineffective for the development of intense social relationships but effective at zero acquaintance. Few studies have in fact analyzed the impressions that narcissists make in the early stages of getting acquainted. As a case in point, Paulhus (1998) found that indeed narcissists made better impressions on peers after an initial interactive group meeting (short-term acquaintance).

The present study aimed to detect and decode the impressions that narcissists make at zero acquaintance, that is, when there has been no interaction prior to the judgments. On the basis of a realistic behavioral approach, we investigated (a) whether narcissists are indeed more popular at first sight, (b) which facets of narcissism are most influential in predicting popularity, (c) which aspects of physical appearance and which behaviors explain the popularity of narcissists in real-life situations, and (d) how much information is needed to make narcissists more popular at zero acquaintance.

\section{The Interpersonal Consequences of Narcissism}

Formally, narcissism can be defined as a pervasive pattern of grandiosity, self-focus, and self-importance (American Psychiatric Association, 1994). Since the concept of narcissism has been introduced in the psychological literature (Ellis, 1898; Freud, 1914/1990), many researchers have analyzed the psychological structure and the intra- and interpersonal processes of narcissism. Psychoanalytic theory (e.g., Kernberg, 1980; Kohut, 1977) de- 
scribed narcissists as being overly engaged with the self (ego libido), not valuing others very much (object libido), and having premature relationships with others.

Recent conceptions similarly characterize narcissism as follows:

A grandiose yet vulnerable self-concept [...] underlies the chronic goal of obtaining continuous external self-affirmation. Because narcissists are insensitive to others' concerns and social constraints and view others as inferior, their self-regulatory efforts often are counterproductive and ultimately prevent the positive feedback that they seek-thus undermining the self that they are trying to create and maintain (Morf \& Rhodewalt, 2001, p. 177).

Additionally, the disposition of impulsivity seems to play an important role: Narcissists "lack the self-control necessary to inhibit the behaviors that thwart the attainment of their goals" (Vazire \& Funder, 2006).

In terms of their interpersonal behavior, narcissists are generally described as craving attention and admiration, prone to demonstrating their superiority, and showing arrogant and aggressive communication behavior (Morf \& Rhodewalt, 2001; Vazire \& Funder, 2006). When examining interpersonal self-report correlates, narcissism is, for example, related to disagreeableness, hostility, selfism, and aggressive tendencies (Emmons, 1984, 1987; Raskin, Novacek, \& Hogan, 1991b; Rhodewalt \& Morf, 1995). Altogether, narcissism is thus thought of as a problematic and maladaptive interpersonal trait. But how do others actually react when confronted with a narcissist?

\section{Interpersonal Short-Term Consequences of Narcissism}

Narcissists are more short-term oriented, looking for immediate admiration rather than mutual liking (Emmons, 1989; Morf \& Rhodewalt, 2001). Interestingly, these interpersonal motivations might indeed lead to short-term social benefits. Narcissists are often described as "charming and socially facile," and as a consequence of this charm, we might be "initially attracted to such individuals" (Morf \& Rhodewalt, 2001, p. 177). It is sometimes assumed that "their extraverted behavior and desire to be liked can make them enjoyable to work with initially" and that "narcissists tend to create drama and, thus, are entertaining to watch" (Young \& Pinsky, 2006, p. 470).

Paulhus (1998) conducted one of the rare studies that directly analyzed the effects of narcissism on interpersonal consequences. He investigated student work groups that met weekly for $20 \mathrm{~min}$ for 7 consecutive weeks. In each meeting, a discussion topic was assigned (e.g., positive and negative qualities of the self, worries, and concerns). After the first meeting of the student work groups, narcissistic students were evaluated as more agreeable, conscientious, open, competent, entertaining, and well adjusted by their peers. Another study on perceptions of people with personality disorders showed that targets who exhibited features of histrionic and narcissistic personality disorders were judged as more likable by unacquainted observers on the basis of thin slices $(30 \mathrm{~s})$ of their videotaped behavior during a diagnostic interview (Oltmanns, Friedman, Fiedler, \& Turkheimer, 2004).

Colvin and colleagues (Colvin et al., 1995; Study 3), however, report immediate negative social reactions toward people who self-enhance - a personality characteristic closely related to narcissism (e.g., John \& Robins, 1994): Observers watched video- taped dyadic debates and judged self-enhancers negatively concerning a variety of social behaviors, including bragging, acting irritable, expressing hostility, and exhibiting poor social skills. Observers also judged the self-enhancers as being less liked by their interaction partners. In another recent study, no effects of narcissism on attractiveness ratings based on facial shots could be found, and the authors concluded that narcissists "pose a unique study of self-but not other-admiration" (Bleske-Rechek, Remiker, \& Baker, 2008, p. 424).

\section{Interpersonal Long-Term Consequences of Narcissism}

The study by Paulhus (1998) suggests that narcissists are rather disliked at long-term acquaintance: After the seventh meeting, people who scored higher on narcissism prior to group assignment were rated as less agreeable, less well adjusted, less warm, and more hostile and arrogant by their peers. This pattern of results nicely resembles the self-report correlates of narcissism. Studies on the interpersonal consequences of self-enhancement yielded very similar results: Having an overly positive self-perception has negative psychological implications on a wide range of different indicators, including interpersonal judgments (e.g., Anderson, Ames, \& Gosling, 2008; Colvin et al., 1995; Kwan, John, Robins, \& Kuang, 2008; Robins \& Beer, 2001). Whereas the selfenhancing nature of narcissism is purported to foster self-esteem via certain illusionary intrapersonal mechanisms (Taylor \& Brown, 1988, 1994; Taylor, Lerner, Sherman, Sage, \& McDowell, 2003), it is "over the long term an ineffective interpersonal strategy with both friends and acquaintances and, therefore, the growth or development of self" (Colvin et al., 1995, p. 1161).

To better understand how narcissism affects interpersonal judgments after short-term and long-term acquaintance, it is first necessary to understand the initial (i.e., zero acquaintance) impressions that others have of narcissists. The effect of narcissism on popularity at zero acquaintance in a real-life context has yet to be studied. In the present study, we aimed to reveal the first impressions that narcissists make and to examine the processes through which narcissism influences these important interpersonal starting points.

\section{A Lens Model Approach for Understanding Narcissism and Popularity at First Sight}

How could narcissism influence popularity at zero acquaintance? To answer this question, one has to consider the processes that lead from personality to interpersonal judgments in general. Process models of interpersonal judgments, like the realistic accuracy model (RAM; Funder, 1995, 1999) or the lens model (Brunswik, 1956; Funder, 2001), have been applied for empirical examinations of the accuracy of interpersonal judgments in realistic contexts (Back, Schmukle, \& Egloff, 2008c; Borkenau \& Liebler, 1992; Funder \& Sneed, 1993; Gosling, Ko, Mannarelli, \& Morris, 2002; Mehl, Gosling, \& Pennebaker, 2006; Vazire, Naumann, Rentfrow, \& Gosling, 2008). According to these models, a target's personality can only be inferred correctly when it is correlated with relevant and observable cues in a given situation and when perceivers observe these cues and use them correctly for their judgments. 
This line of reasoning can be adapted for investigating the popularity of narcissists: Narcissism can only influence popularity when (a) it correlates with observable cue differences in a given situation (e.g., narcissism leads to smiling) and (b) perceivers consensually observe and use these cues in their attraction ratings (e.g., smiling leads to liking). According to this lens model approach to narcissism and popularity, the interpersonal success of narcissists at first sight depends on the cues they immediately produce when meeting others for the first time. At zero acquaintance, we do not have any direct information about the thoughts, feelings, opinions, preferences, or the life stories of others. However, even first impressions offer some information about targets. Most important, at zero acquaintance the targets' physical appearance and thin slices of their nonverbal and verbal behaviors are accessible. On the basis of our lens model approach, we expect that narcissists are indeed more popular at first sight because they produce physical, nonverbal, and verbal cues that are related to four generally valued aspects of targets: attractiveness, competence, interpersonal warmth, and humor (Berscheid \& Reis, 1998).

Physical attractiveness is associated with social benefits in a number of relevant situations: Physically attractive people are generally more liked and are evaluated more positively than less attractive people (Berscheid \& Reis, 1998; Eagly, Ashmore, Makhijani, \& Longo, 1991; Feingold, 1992; Jackson, Hunter, \& Hodge, 1995; Langlois et al., 2000). At zero acquaintance, narcissists may appear more attractive because they are more likely to wear expensive, flashy, and neatly kept clothing as well as a more dressed-up hairstyle (Vazire et al., 2008). These easily accessible and salient cues are expected to be positively evaluated by most perceivers at zero acquaintance.

At zero acquaintance, competence is most clearly conveyed by nonverbal signs of dominance or social potency (Ellyson \& Dovidio, 1985), cues that have been shown to influence the positivity of interpersonal judgments (DePaulo, 1992; Keating et al., 1981; Murphy, 2007). For instance, nonverbal body signals of self-assuredness (e.g., stooped vs. straight posture) might foster popularity. Narcissism is among other characteristics defined by striving for dominance, entitlement, and superiority (Emmons, 1987; Raskin \& Hall, 1979). Self-promotional coping processes of narcissists might protect self-esteem in the stressful context of meeting important others for the first time (Taylor, Wayment, \& Collins, 1993) and, as a consequence, contribute to more selfassured and less nervous behavior. Their motivation and ability to self-present is even higher when the opportunity is given to enhance and compare themselves (Wallace \& Baumeister, 2002). Moreover, many of the problematic dominance-oriented communicative behaviors of narcissists, which are usually perceived as threatening and arrogant, are not apparent at zero acquaintance. Although their tendency to manipulate others and to show off is not an effective strategy in the long run, it is more likely to lead to a favorable impression at first sight (Tice, Butler, Muraven, \& Stillwell, 1995).

Interpersonal warmth at first sight is most strongly related to nonverbal facial cues: The attentiveness, friendliness, and selfassuredness of facial expressions should influence attraction at first sight (Cashdan, 1998; Friedman, Riggio, \& Casella, 1988; Harker \& Keltner, 2001; Reis et al., 1990; Shrout \& Fiske, 1981). Narcissists are used to and enjoy presenting themselves and experience a rise in positive affect during an evaluative performance
(Robins \& Beer, 2001). Narcissists are moreover often described as having a charismatic air (Morf \& Rhodewalt, 2001; Young \& Pinsky, 2006), which has been defined as "a dramatic flair involving the desire and ability to communicate emotions and thereby inspire others" (Friedman et al., 1988, p. 204). They also tend to be more impulsive (Vazire \& Funder, 2006). All of this should provide them with a more charming facial expression at first sight.

Moreover, the same dispositional (being impulsive), motivational (desire to present themselves), affective (enjoy presenting themselves), and behavioral tendencies (ability to entertain others) should make narcissists appear more humorous. Joking around and contributing original or witty verbal expressions might contribute to the narcissist's charisma.

In summary, we assume that narcissism predicts all of the four relevant cue domains - attractiveness, from their flashy and neat attire; interpersonal warmth, from their charming glances at strangers; competence, from their self-assured behavior; and humor, from their witty verbal expressions. As a result, they thus should enjoy greater initial popularity than non-narcissists.

\section{Facets of Narcissism and Popularity at First Sight}

According to Emmons $(1984,1987)$, four facets of narcissism can be distinguished: Leadership/Authority (L/A; enjoying being a leader and being seen as an authority), Self-Absorption/SelfAdmiration (S/S; admiring one's own physical appearance and personality), Superiority/Arrogance (S/A; overestimation of one's own abilities, underlying themes of superiority and grandiosity), and Exploitativeness/Entitlement (E/E; interpersonal manipulation, expectations of favors, exploitation of others). These facets are only moderately intercorrelated.

Most important, they are thought not only to represent different aspects of narcissism but also to differ in their adaptiveness. The L/A facet correlates with many self-reported personality characteristics that are conceived of as being beneficial, like extraversion, warmth, social boldness, dominance, lower neuroticism, and a less negative self-focus (Emmons, 1984, 1987). People who score high on this subscale report more overall social support as well as less perceived psychological distress (Rhodewalt \& Morf, 1995). It is thus assumed that this component "may represent healthier aspects of narcissism" (Emmons, 1987, p. 14).

In contrast, the $\mathrm{E} / \mathrm{E}$ component is thought to "tap the maladaptive and possibly pathological aspects of narcissism" (Emmons, 1987, p. 14). It correlates positively with self-reported measures of neuroticism, anxiety, tenseness, aggression, and suspiciousness (Emmons, 1984), and a number of other psychological problems (Raskin \& Novacek, 1989). This facet of narcissism is related to a lack of empathy and agreeableness, a lower perceived availability of communication partners, and a greater number of self-reported hassles (Rhodewalt \& Morf, 1995; Watson, Grisham, Trotter, \& Biderman, 1984). It is moreover the only facet that correlates with measures of pathological narcissism (Emmons, 1984).

Research on the interpersonal reactions that narcissists actually evoke has, however, only concentrated on narcissism as a unique construct thus far. What about the facets' influence on popularity at first sight? Following past research on narcissism facets, the most adaptive aspect of narcissism is the L/A facet and the most maladaptive aspect is the E/E facet (Emmons, 1984, 1987; Raskin $\&$ Novacek, 1989). According to this view, enjoying being a leader 
and being seen as an authority figure generally have fewer negative and some positive interpersonal consequences, whereas a sense of entitlement and a tendency toward interpersonal manipulation and exploitation of others are clearly interpersonally disadvantageous. Following this "consistent specificity" hypothesis, the generally adaptive L/A facet should rather lead to popularity, whereas the generally maladaptive E/E facet should lead to unpopularity at zero acquaintance.

When considering the relevant intrapersonal processes and observable cues at zero acquaintance, the specific influence of narcissism facets could, however, also be different. First, the positive aspects of L/A might be difficult to recognize at zero acquaintance. Perhaps more intense and task-oriented interactions are needed to show that one is an authority and knows how to lead others. Second, people high in E/E should be most strongly motivated to make a good impression on their peers because the narcissist's striving for admiration is most strongly pronounced in the $\mathrm{E} / \mathrm{E}$ component (Emmons, 1984; Morf \& Rhodewalt, 2001). As a consequence, they should show more effort to impress their peers. Third, E/E tendencies are related to higher social desirability scores (Watson et al., 1984), higher public self-consciousness, and a more other-directed self-monitoring style than other facets of narcissism (Emmons, 1984), which can lead to a more streamlined appearance and behavior at zero acquaintance. Fourth, E/E narcissists have higher manipulation motivations and habits and are thus well trained and experienced in influencing others. Their higher effort to impress others may thus indeed be successful, even more because manipulative and showing-off behaviors are more effective at zero acquaintance (Tice et al., 1995). Fifth, in contrast to other facets of narcissism, E/E narcissists are known to have a higher affective intensity and variability (Emmons, 1987): They show more emotions and more variable emotions, potentially making them more salient and charming at first sight. Following this "paradoxical specificity" hypothesis, L/A should have no relevant effect on popularity at zero acquaintance, whereas E/E narcissists should positively impress their peers because they most strongly possess the kinds of intrapersonal processes and observable cues that should make narcissists popular at first sight.

\section{The Present Research}

In the present research, we investigated the popularity of narcissists at zero acquaintance. We analyzed (a) whether narcissists are indeed more popular at first sight, (b) which facets of narcissism are most important for determining popularity, (c) how these narcissism-popularity links can be explained by actual appearances and behaviors at first sight, and (d) how much information is necessary to make narcissists popular at first sight.

\section{Are Narcissists Really More Popular at First Sight?}

To date, there are only a few studies that have investigated the early interpersonal consequences of narcissism and related traits, with some showing a positive effect (Oltmanns et al., 2004; Paulhus, 1998) and other studies finding no effect (Bleske-Rechek et al., 2008) or a negative influence on interpersonal judgments (Colvin et al., 1995). Interpersonal consequences of narcissism at zero acquaintance in a meaningful social context have not yet been investigated. On the basis of a lens model approach, we expected narcissists to be more popular at first sight.

\section{Which Facets of Narcissism Lead to Popularity at First Sight?}

A number of narrower traits can be distinguished, which together make up the broader personality construct of narcissism. These facets of narcissism are reported to differ with respect to their adaptive value (Emmons, 1984, 1987; Raskin \& Novacek, 1989). We thus analyzed which specific facets of narcissism correlate with being liked at zero acquaintance. According to the consistent specificity hypothesis, the $\mathrm{E} / \mathrm{E}$ facet is rather unattractive, whereas the L/A facet fosters popularity. In contrast, the paradoxical specificity hypothesis assumes that the E/E facet should be most strongly related to popularity, whereas L/A should have no impact on being liked at zero acquaintance.

\section{Which Physical Appearances and Behavioral Cues Mediate the Effect of Narcissism on Popularity at First Sight?}

Finally, we aimed to gain a more detailed and realistic insight into narcissism and popularity at first sight. To find out why narcissism is related to popularity at first sight, we analyzed how narcissism manifests at first sight and which of the observable cues lead to popularity. To this end, we included those aspects of physical appearance and nonverbal behavior that are observable at zero acquaintance. Most important, we expected that the influence of narcissism on popularity is mediated by the flashiness and neatness of the target's dress, the charming quality of their facial expression, the self-assuredness of their nonverbal body movements, and the humorousness of their verbal expressions.

\section{How Much Information Is Necessary to Make Narcissists Popular at First Sight?}

Albeit first impressions occur in almost no time and without much effort (e.g., Bar, Neta, \& Linz, 2006; Duckworth, Bargh, Garcia, \& Chaiken, 2002), interpersonal attraction at zero acquaintance in a real-life context relies on a variety of different kinds of information provided by targets: Physical cues like clothing and hairdo; nonverbal cues like gestures, mimicry, and posture; and verbal cues like the content of what targets say.

In the context of personality judgments at zero acquaintance, it has been shown that thin slices of behavior are sufficient for producing accurate impressions (e.g., Borkenau \& Liebler, 1992; Borkenau, Mauer, Riemann, Spinath, \& Angleitner, 2004; Funder \& Sneed, 1993; Levesque \& Kenny, 1993; Mehl et al., 2006). In many cases, thinning the slices (shortening the presentation time or reducing the number of qualitatively different kinds of information) did not even result in a relevant loss of accuracy (Ambady \& Rosenthal, 1992, 1993; Ambady \& Skowronski, 2008; Borkenau \& Liebler, 1992).

In a similar fashion, we additionally wanted to analyze how much information is needed to make narcissists more popular at first sight. Do observers have to be in the same room to "breathe" the narcissist's charismatic air? Are the voices of narcissists necessary for making them popular? What about the importance of 
nonverbal information-could nice clothing suffice for impressing others at first sight? To answer these questions, we systematically reduced the amount of information observer judgments were based on.

\section{Study 1: Real-Life Judgments (Round-Robin)}

In Study 1, we aimed to examine popularity at first sight while simultaneously using a realistic and meaningful social context for both targets and perceivers involving a self-introduction to and judging of unacquainted but prospectively important others. Are narcissists really more popular in such a situation? Moreover, we wished to determine whether facets of narcissism differ in their impact on interpersonal attraction at zero acquaintance. Finally, we aimed to explain the narcissism-popularity link at first sight. We expected that theoretically derived physical appearances and nonverbal and auditory cues would be correlated with both narcissism and popularity and would mediate the impact of narcissism and its facets on popularity.

\section{Method}

Participants. A single age-group of psychology freshmen encountering one another for the first time was investigated. Participants were 52 female and 21 male students from various places of origin in Germany. ${ }^{1}$ Their average age was 22.32 years $(S D=$ 4.57). Of importance is that they were unacquainted before the start of the experiment. ${ }^{2}$

Procedure. The experiment took place at the beginning of an introductory session for freshmen studying psychology. Students received a randomly assigned seat number when entering the room and took their assigned place. Beginning at the right-hand side of each row, they were then requested to individually step forward to a marked spot on the floor and briefly introduce themselves. These self-introductions were videotaped and ranged in length from 4.00 to $21.30 \mathrm{~s}(M=7.49, S D=2.99)$. Immediately after each introduction, participants were evaluated by the other freshmen. Following evaluation, the students in each respective row all moved one seat to the right, and the evaluated participant took the empty seat at the far left-hand side of the row. This procedure was repeated, row by row, until all students had been rated. Finally, participants were administered a questionnaire to be completed at home.

Narcissism measures. For the measurement of narcissism and its facets, targets filled out the German version (Schütz, Marcus, \& Sellin, 2004) of the Narcissistic Personality Inventory (NPI; Raskin \& Terry, 1988). In addition to the global measure of narcissism, the Emmons' $(1984,1987)$ four facets of the NPI were computed.

Cue measures. Self-introduction videos were technically edited to obtain (a) a still photograph of the body, (b) the silent film, and (c) the auditory tape for each target. These files were then used to obtain multiple cue values for each target. To this end, four groups of independent and trained observers (four observers per group) rated (a) physical cues (e.g., colorfulness of dress) based on pictures of the body, (b) nonverbal body cues (e.g., stooped vs. straight posture) and (c) nonverbal facial cues (e.g., friendly vs. grumpy facial expression) based on the silent film, and (d) verbal cues (e.g., conventional vs. original introduction) based on the sound only. The selection of cues was designed to cover all of the relevant cue domains and was inspired by other established systems of behavioral observation (e.g., Asendorpf, 1987; Back, Schmukle, \& Egloff, in press; Borkenau \& Liebler, 1992; Egloff \& Schmukle, 2002; Funder, Furr, \& Colvin, 2000).

Ratings for stylishness of hair ranged from 1 (not at all) to 7 (very much). All other ratings were performed on scales ranging from 1 (not at all) to 6 (very much). Reliabilities of cue value ratings ranged from .66 for "unfashionable versus fashionable dress" to .87 for "conventional-original content of speech," with a mean alpha coefficient of $.80(S D=0.06 ; M d n=.81)$. Objective cue values were additionally gathered by categorization (e.g., uses a salutation). Cue values were $z$ standardized and averaged to obtain aggregate cue measures of "flashy and neat dress" (uncolored-colorful dress, unfashionable-fashionable dress, casual-chic dress, unstylish-stylish dress, unstylish-stylish hair), "charming facial expression" (timid-self-assured facial expression, grumpy-friendly facial expression), "self-assuredness of body movements" (stooped-straight posture, withdrawn-dominant behavior, awkward-smooth body movement), and "humorous verbal expression" (uses a salutation, conventional-original introduction, serious-casual introduction). Reliabilities of these cue aggregates were $\alpha=.75$ for "flashy and neat dress," $\alpha=.57$ for "charming facial expression," $\alpha=.67$ for "self-assuredness of body movements," and $\alpha=.56$ for "humorous verbal expression. ${ }^{3}$

Popularity measure. Each participant rated all other students on two rating scales intended to measure interpersonal attraction that ranged from 0 (not at all) to 5 (very much) ("How likeable do you find this person?", "Would you like to get to know this person?"). This resulted in a large round-robin design with $73 \times$ $72 \times 2=10,512$ ratings. Bivariate social relations analyses for round-robin data (Bond \& Lashley, 1996; Kenny, 1994; Kenny, Kashy, \& Cook, 2006) indicated that the attraction ratings each

\footnotetext{
${ }^{1}$ The analyses reported in this study are based on data that were collected in the "Mainz Freshman Study" (MFS). This is the third article to come out of the extensive MFS data set, and the analyses do not overlap with the previous projects, which focused on a combination of the lens model and the social relations model (Back et al., 2008b), and the effect of seat assignment on friendship development (Back, Schmukle, \& Egloff, 2008a).

${ }^{2}$ Although previous acquaintance between participants was highly unlikely, we asked participants about prior acquaintance between each pair of students. Out of the total sum of 2,628 dyads $(73 \times 72 / 2)$, only 10 indicated prior acquaintance. Treating the ratings of these dyads as missing data did not change results in any significant way.

${ }^{3}$ In light of the broadness of the cue aggregates and the limited number of multiply determined, single behavioral indicators, we regarded these numbers as acceptable. Additionally, we would like to point out that when analyzing the reliability of behavioral measures, it is necessary to consider the individual specificity of behavioral responses (see Asendorpf, 1988, for a detailed discussion). Many behavioral indicators (e.g., verbal humor) that can be identified at the group level (e.g., using an original expression) are not interchangeable at the individual level. Some people show their humor by using an introduction, others by being very original, and others by being very casual. This unavoidably leads to low internal consistency of the behavioral aggregate. In a study on the behavioral assessment of shyness, Asendorpf (1988) was, however, able to show that an aggregate of behavioral measures with low intercorrelations can nevertheless be a valid behavioral indicator.
} 
contained a significant portion of perceiver variance (13\%), target variance $(13 \%)$, and relationship variance $(49 \%)$ (all $p$ s $<.001)$. Target variance is a measure of consensus and indicates the extent to which some targets received higher attraction ratings (are popular) and others received lower attraction ratings (are unpopular). There was thus a highly significant agreement between perceivers for who was likable and who was not. Target effects of attraction for each participant constituted our measure of popularity at first sight.

\section{Results}

Means, standard deviations, and intercorrelations for the narcissism measures can be found in Table 1. In order to find out whether narcissists were more popular at first sight, we correlated the targets' narcissism scores with popularity scores (see Table 2). Results revealed that narcissists are popular at first sight. This positive interpersonal effect was more pronounced for the $\mathrm{E} / \mathrm{E}$ facet.

To explain why narcissism in general and the E/E facet in particular had such a positive interpersonal effect, we conducted lens model analyses by examining the observable physical, nonverbal, and verbal cues (see Table 3). First, we analyzed whether narcissism is related to these cues at zero acquaintance. Therefore, we computed partial correlations between each narcissism measure and all of the single cues as well as the cue aggregates, thereby controlling for the targets' gender and age. ${ }^{4}$ As can be seen on the left-hand side of Table 3, narcissism and its facets were substantially related to all of the cue domains with somewhat more consistent and stronger correlations for the E/E facet. Second, we analyzed what kinds of observable cues predicted popularity scores. As can be seen on the right-hand side of Table 3 , all of the cue domains that were related to narcissism also predicted being liked by involved observers. A path analysis using Mplus (Muthén \& Muthén, 2006) showed that the effect of narcissism was mediated by the observable cues it elicits at zero acquaintance (indirect effect $=$ $.256, p<.05$; direct effect $=-.034, n s)$. The same was true for the effect of $\mathrm{E} / \mathrm{E}$ on popularity (indirect effect $=.211, p<.05$; direct effect $=.038, n s$ ).

\section{Discussion}

According to our lens model approach, narcissism can only influence interpersonal attraction at first sight when (a) narcissism is related to observable cues in the given situation and (b) perceivers detect these cues and use them for their attraction judgments at zero acquaintance (Back, Schmukle, \& Egloff, 2008b; Funder, 1995). Both prerequisites were met in Study 1 . The main results of this study are summarized in Figure 1: In the situation in which individuals introduced themselves to potentially meaningful peers, narcissists exhibited neater and flashier appearances, more charming facial expressions, more self-assured body movements, and more humorous verbal expressions. Of importance is that these cues were evaluated as positive by unacquainted peers. Consequently, narcissists were indeed more popular at first sight. The zero acquaintance adaptiveness of narcissism was moreover mainly due to the positive impact of the E/E facet. In accordance with the paradoxical specificity hypothesis and in contrast to the consistent specificity hypothesis, those with a sense of entitlement and a tendency to exploit others most strongly impressed their fellow students at first sight.

\section{Study 2: Video-Based Judgments (Full Information)}

In Study 2, we aimed to investigate the impressions that narcissists make on others who are exposed to the full amount of information available from the short videotaped selfintroductions from Study 1. In comparison to involved perceivers from Study 1, unacquainted observers in Study 2 did not perceive targets in such an immediate way (they were not in the same room), making it impossible to "breathe" the narcissist's charismatic air. Moreover, perceivers knew that they were not evaluated themselves and that they would never meet the targets they were asked to judge-targets were thus unimportant to them. Would narcissists nevertheless impress perceivers at zero acquaintance? We wanted to determine whether (a) narcissists are liked more than their peers by uninvolved perceivers at zero acquaintance, (b) the effect of narcissism on immediate social judgments is again specifically positive for the E/E facet, and (c) results can be explained by the observable cues that were theoretically derived.

\section{Method}

Observers. Ninety-five participants (57 women) served as observers in exchange for research participation credit or monetary compensation. Their average age was 24.61 years $(S D=4.20)$.

Procedure. Videotaped self-introductions from Study 1 were separately stored for each target. These files were then used to obtain the interpersonal judgments on a personal computer using the program Inquisit (Draine, 2001). Participants were seated in front of a computer in separate cubicles. They were informed that they would be required to make a series of attraction ratings. In each trial, one of the video files was presented. Immediately after presentation, rating scales were displayed and observers evaluated the target. There was no time constraint for evaluations, but observers were instructed as follows: "You don't have to think too much about your evaluations, just respond as spontaneously as possible." Trial order was randomized.

Popularity measure. Observers rated each target on two rating scales intended to measure interpersonal attraction that ranged from 0 (not at all) to 5 (= very much) ("likable," "simpatico"). Individual popularity measures for each observer were computed by averaging across these items. There was substantial consensus for who was evaluated positively and who was evaluated negatively, intraclass correlation $[\mathrm{ICC}](2, \mathrm{k})=.95$, $\operatorname{ICC}(2,1)=.16, p<.001$. A total popularity measure was then obtained by aggregating individual popularity measures across observers.

\section{Results}

In order to find out whether narcissists really were more popular at first sight, we correlated popularity with the targets' narcissism

\footnotetext{
${ }^{4}$ Gender and age had almost no effect on any of our analyses. Accordingly, when not controlling for gender and age, results were very similar for all of the cue analyses reported in the article.
} 
Table 1

Descriptive Statistics and Intercorrelations for Targets' Narcissism Scores

\begin{tabular}{|c|c|c|c|c|c|c|}
\hline Predictor & $M$ & $S D$ & L/A & $\mathrm{S} / \mathrm{S}$ & S/A & $\mathrm{E} / \mathrm{E}$ \\
\hline NPI & 15.96 & 6.81 & $.78^{\text {***** }}$ & $.74^{* * * *}$ & $.76^{* * * *}$ & $.69^{* * * *}$ \\
\hline Leadership/Authority subscale & 3.53 & 2.11 & & $.35^{* *}$ & $.56^{* * * *}$ & $.44^{* * * *}$ \\
\hline Self-absorption/Self-admiration subscale & 3.30 & 2.24 & & & $.39^{* * * *}$ & $.36^{* * *}$ \\
\hline Superiority/Arrogance subscale & 3.51 & 1.97 & & & & $.45^{* * * *}$ \\
\hline Exploitativeness/Entitlement subscale & 1.88 & 1.42 & & & & \\
\hline
\end{tabular}

Note. $\quad$ NPI $=$ Narcissistic Personality Inventory total score; L/A $=$ Leadership/Authority subscale of the NPI; S/S $=$ Self-absorption/Self-admiration subscale of the NPI; S/A = Superiority/Arrogance subscale of the NPI; E/E = Exploitativeness/Entitlement subscale of the NPI. The possible range of means is $0-40$ for the NPI; $0-8$ for $\mathrm{L} / \mathrm{A}, \mathrm{S} / \mathrm{S}$, and $\mathrm{S} / \mathrm{A}$; and $0-7$ for $\mathrm{E} / \mathrm{E}$.

${ }^{* * *} p<.01 .{ }^{* * * *} p<.001$ (one-tailed).

scores (see Table 4, Column 1). Results revealed an interpersonal advantage for narcissists at first sight: They were more liked. However, this narcissism-popularity link was not uniformly present for each of the narcissism facets. Whereas the L/A facet was virtually uncorrelated with first impressions, the E/E facet significantly predicted popularity at first sight. How could narcissism affect popularity at first sight? As can be seen in Column 1 of Table 5, all of the cue domains that were related to narcissism also predicted popularity. People, for instance, who wore more colorful clothing, had more friendly facial expressions, exhibited straighter body posture, or spoke with more casual verbal expressions were immediately liked more. For a more formal test of our mediational hypothesis, we performed a path analysis using Mplus (Muthén \& Muthén, 2006). Results showed that the popularity of narcissists was indeed mediated by the flashiness and neatness of dress, the charming quality of facial expression, the self-assuredness of body movements, and the amount of expressed verbal humor (indirect effect $=.226, p<.05$; direct effect $=.005, n s$ ). The same cues mediated the effect of $E / E$ on popularity (indirect effect $=.180, p<.05$; direct effect $=.123, n s)$.

\section{Discussion}

In Study 2, we were able to show that narcissists indeed made a positive impression on strangers at zero acquaintance. Unacquainted observers judged narcissists more favorably when exposed to very brief video clips of their self-introductions. Moreover, this positive effect was even more pronounced for the facet described as the most maladaptive one: E/E. By including all of the relevant observable physical, nonverbal, and

Table 2

Narcissism as a Predictor of Popularity at First Sight (Study 1: Meaningful Social Situation)

\begin{tabular}{lc}
\hline \multicolumn{1}{c}{ Predictor } & $\begin{array}{c}\text { Popularity } \\
\text { (peer ratings) }\end{array}$ \\
\hline Narcissism & $.21^{*}$ \\
Leadership/Authority subscale & .08 \\
Self-absorption/Self-admiration subscale & .14 \\
Superiority/Arrogance subscale & .13 \\
Exploitativeness/Entitlement subscale & $.25^{*}$ \\
\hline$* p<.05$ (one-tailed). &
\end{tabular}

auditory cues of targets, we were able to explain narcissists' popularity at fist sight. Mediational analyses suggest that narcissists were more popular because they had a more neat and flashy appearance, a more charming facial expression, more self-assured body movements and, in the case of the E/E facet, more humorous verbal expressions, all of which had a positive impact on their peers.

Thus, investigating video-based judgments of uninvolved observers, we were able to fully replicate the results of our real-life judgment analyses. When observers (whether involved or not) were exposed to the physical, nonverbal, and auditory information from targets' self-introductions, narcissism led to popularity. We then aimed to replicate this pattern of results after further reducing the amount of information the attraction judgments were based on.

\section{Study 3: Video-Based Judgments (No Sound)}

Narcissism predicted popularity in a group of unacquainted observers who were exposed to the full information available from the targets' self-introduction videos (Study 2). In Study 3, we wanted to analyze whether this effect would persist when observers had no auditory information (video without sound), thereby omitting the verbal expression cues. Moreover, the specific impact of the E/E facet of narcissism was to be verified. Finally, we wanted to establish whether the remaining physical and nonverbal cues mediated the effect of narcissism on popularity.

\section{Method}

Observers. Sixty-eight participants (49 women) served as observers in exchange for research participation credit or monetary compensation. Their average age was 21.16 years $(S D=3.43)$.

Procedure and popularity measure. Videotaped selfintroductions from Study 1 were technically edited to obtain a silent film for each target. These files were then used to obtain the interpersonal judgments on a personal computer using the program Inquisit (Draine, 2001). The judgment procedure was as described in Study 2. Again, there was substantial consensus in attraction ratings, $\operatorname{ICC}(2, \mathrm{k})=.94, \operatorname{ICC}(2,1)=.18, p<.001$. A total popularity measure was obtained by aggregating individual popularity measures across observers. 
Table 3

A Lens Model Analysis of Narcissism at First Sight (Study 1: Meaningful Social Situation)

\begin{tabular}{|c|c|c|c|c|c|c|}
\hline \multicolumn{5}{|c|}{ Narcissism } & \multirow[b]{2}{*}{ Observable cues } & \multirow[b]{2}{*}{ Popularity } \\
\hline NPI & L/A & $\mathrm{S} / \mathrm{S}$ & S/A & $\mathrm{E} / \mathrm{E}$ & & \\
\hline $.44^{* * * *}$ & $.26^{*}$ & $.30^{* *}$ & $.27^{*}$ & $.34^{* *}$ & Flashy and neat dress & $.29^{* * *}$ \\
\hline $.47^{* * * * *}$ & $.32^{* *}$ & $.34^{* * *}$ & $.27^{*}$ & $.40^{\text {***** }}$ & Uncolored-colorful dress & $.22 *$ \\
\hline $.28^{* * *}$ & .16 & .17 & .19 & $.21^{*}$ & Unfashionable-fashionable dress & .19 \\
\hline $.33^{* * *}$ & $.24^{*}$ & .18 & .15 & $.28^{* *}$ & Casual-chic dress & .16 \\
\hline $.34^{* * *}$ & $.24^{*}$ & .18 & $.30^{\text {*** }}$ & $.24^{*}$ & Unstylish-stylish dress & $.22^{*}$ \\
\hline .17 & -.01 & $.21^{*}$ & .09 & .11 & Unstylish-stylish hair & $.26^{*}$ \\
\hline $.31^{* * *}$ & .13 & $.24^{*}$ & .19 & $.24^{*}$ & Charming facial expression & $.65^{* * * *}$ \\
\hline $.31^{* * *}$ & .12 & $.28^{* *}$ & .15 & .19 & Timid-self-assured facial expression & $.47^{* * * * *}$ \\
\hline $.21^{*}$ & .09 & .11 & .18 & $.20^{*}$ & Grumpy-friendly facial expression & $.61^{* * * *}$ \\
\hline $.44^{* * * *}$ & $.22^{*}$ & $.41^{* * * *}$ & $.28^{* * *}$ & $.31^{* *}$ & Self-assuredness of body movements & $.48^{* * * *}$ \\
\hline $.39^{* * * *}$ & $.24^{*}$ & $.26^{*}$ & $.31^{\text {** }}$ & $.29^{* *}$ & Stooped-straight posture & $.44^{* * * *}$ \\
\hline $.33^{* * *}$ & .16 & $.36^{* *}$ & .13 & .19 & Withdrawn-dominant behavior & $.30^{* * *}$ \\
\hline $.33^{* * *}$ & .12 & $.34^{* *}$ & $.23^{*}$ & $.26^{*}$ & Awkward-smooth body movement & $.38^{* * * *}$ \\
\hline .03 & -.07 & -.03 & .07 & $.21^{*}$ & Humorous verbal expression & $.34^{* *}$ \\
\hline .06 & -.01 & .08 & .06 & .14 & Uses a salutation & .13 \\
\hline .00 & -.06 & -.13 & .06 & .15 & Conventional-original introduction & $.30^{\text {*** }}$ \\
\hline .00 & -.09 & -.02 & .03 & .16 & Serious-casual introduction & $.33^{\text {*** }}$ \\
\hline
\end{tabular}

Note. Target age and gender were partialed out of correlations for all cues. Narcissism-cue and cue-popularity correlations for aggregate cue measures are shown in boldface italics. NPI = Narcissistic Personality Inventory total score; L/A = Leadership/Authority subscale of the NPI; S/S = Self-absorption/Self-admiration subscale of the NPI; S/A = Superiority/Arrogance subscale of the NPI; E/E = Exploitativeness/Entitlement subscale of the NPI.

${ }^{*} p<.05 .{ }^{* *} p<.01 .{ }^{* * *} p<.001$ (one-tailed).

\section{Results}

Correlations between narcissism scores and popularity can be seen in the second column of Table 4 . Whereas there was no effect of the L/A facet and a higher but nonsignificant effect of the narcissism total score, the $\mathrm{E} / \mathrm{E}$ facet was again related to popularity at first sight. As can be seen in the second column of Table 5, all of the physical and nonverbal cue domains that were related to $\mathrm{E} / \mathrm{E}$ also predicted popularity. Path analysis using Mplus (Muthén \& Muthén, 2006) revealed that the popularity of narcissists who have a sense of entitlement and tend to exploit others was mediated by these cues: the flashiness and neatness of dress, the charming quality of facial expression, and the self-assuredness of body movements (indirect effect $=.184, p<.05$; direct effect $=$ $.047, n s)$

\section{Discussion}

In Study 3, we analyzed popularity based on brief soundless self-introductions. Results showed that there was a specific positive effect of the E/E facet of narcissism on popularity even when observers had no auditory information. This effect could moreover again be explained by including the remaining observable cues: E/E narcissists seemed to be more popular because they had neater and flashier appearances, more charming facial expressions, and more self-assured body movements.

\section{Study 4: Video-Based Judgments (Still Photo of Body)}

In a final study, we further reduced the amount of material available for judgments and used still photographs of the body with the face removed. This was to test whether the specific effect of E/E on popularity would emerge when attraction judgments were based on dress-related cues only.

\section{Method}

Observers. Forty-five participants (22 women) served as observers in exchange for research participation credit or monetary compensation. Their average age was 26.06 years $(S D=4.63)$.

Procedure and popularity measure. Videotaped selfintroductions from Study 1 were technically edited to obtain a still photograph of the body (with the face removed) for each target. These files were then used to obtain the interpersonal judgments on a personal computer using the program Inquisit (Draine, 2001). The judgment procedure was as described in Study 2. Again, there was substantial consensus in attraction ratings, $\operatorname{ICC}(2, \mathrm{k})=.91$, $\operatorname{ICC}(2,1)=.18, p<.001$. A total popularity measure was obtained by aggregating individual popularity measures across observers.

\section{Results}

Correlations between narcissism and popularity can be found in the third column of Table 4. Again, the E/E facet was related to popularity at first sight: Unacquainted observers who saw only a still photograph of the target's body with the face removed evaluated E/E narcissists more positively. Again, a zero correlation was found for the L/A facet and an intermediate effect for the total score. As can be seen in the third column of Table 5, dress cues that were related to E/E also predicted popularity. Consequently, the flashiness and neatness of dress alone explained the positive effect of $\mathrm{E} / \mathrm{E}$ narcissists (indirect effect $=.149, p<.05$; direct effect $=.030, n s)$.

\section{Discussion}

Study 4 revealed that the positive interpersonal effect of $\mathrm{E} / \mathrm{E}$ is already apparent when the target's clothing is observed: E/E nar- 


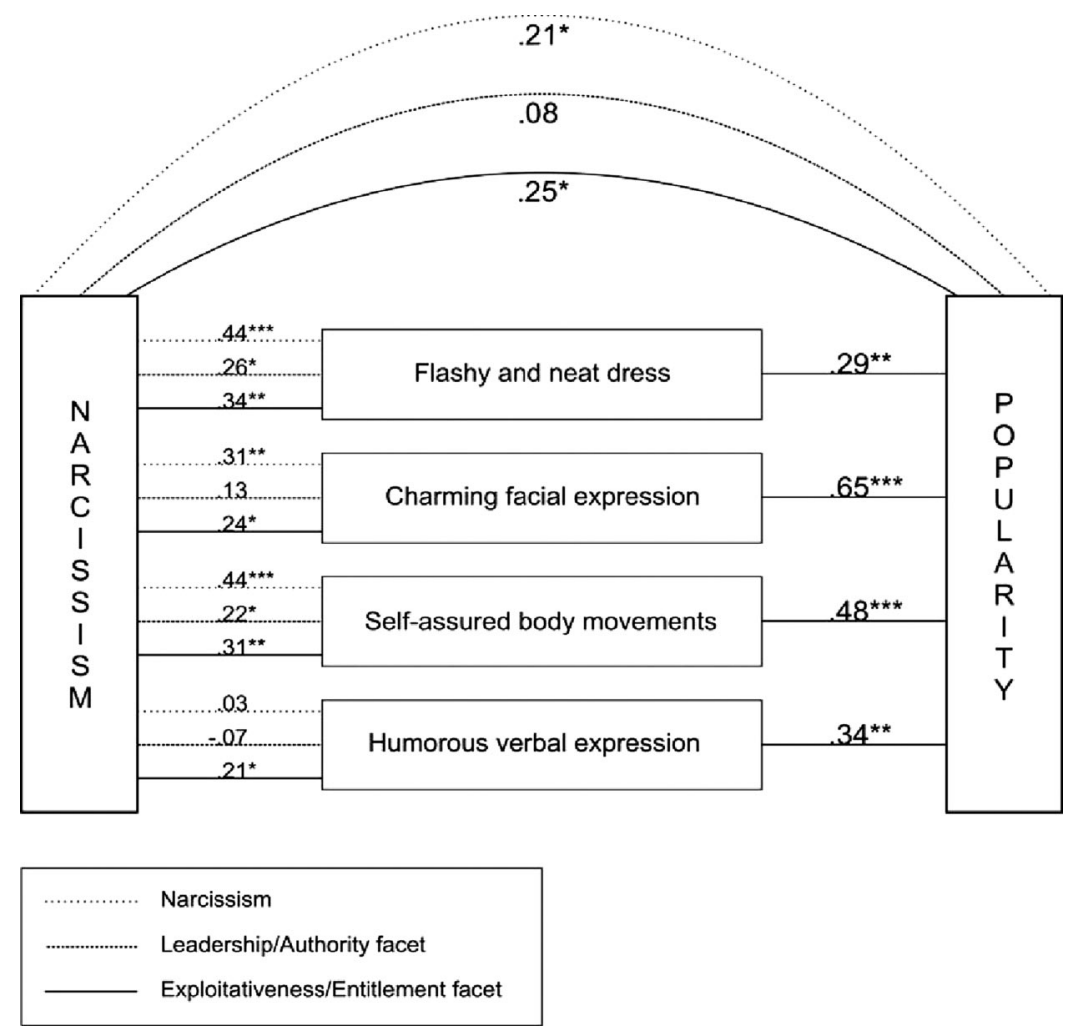

Figure 1. Lens model analysis of narcissism and popularity at first sight. The values on the curves of the figure reflect the correlation of the narcissism full scale, the Leadership/Authority (L/A) facet, and the Exploitativeness/ Entitlement (E/E) facet with popularity. Personality-cue correlations are depicted on the left-hand side and refer to associations between observable cues and narcissism (Column 1), L/A (Column 2), and E/E (Column 3), respectively. On the right-hand side, cue-popularity correlations are presented. All cue correlations were computed controlling for the targets' gender and age. ${ }^{*} p<.05 .{ }^{* *} p<.01 .{ }^{* * * *} p<.001$ (one-tailed).

cissists can impress strangers by the flashiness and neatness of their physical appearance alone. ${ }^{5}$

\section{General Discussion}

\section{The Popularity of Narcissists at First Sight}

The present research aimed to detect and decode the impressions that narcissists make at first sight. Specifically, we were interested in four research questions. First, the popularity of narcissists was examined. Second, we investigated which facets of narcissism are most influential in predicting popularity. Third, we determined which aspects of physical appearance and behavior explain the interpersonal consequences of narcissism in a real-life situation. Fourth, we analyzed the amount of information that is necessary for revealing the effects of narcissism on popularity.

Are narcissists really more popular at first sight? When perceivers were exposed to the full amount of information available from targets' appearances and behaviors at zero acquaintance, a significant positive effect of narcissism on popularity was found. Narcissists indeed make a positive impression on strangers. This was found for uninvolved as well as for highly involved perceivers. Thus, despite the negative interpersonal consequences of narcissism in long-term relationships, narcissists are more popular at first sight.

Interestingly, recent findings also show that narcissism is detectable at zero acquaintance (Vazire et al., 2008). Observers thus seem to

\footnotetext{
${ }^{5}$ As supplementary analyses, we also examined attraction ratings of uninvolved perceivers in an "audio only" condition $(N=127)$ based on the same videotaped self-introductions from Study 1. Results showed that narcissism was not related to popularity based on the voice information alone $(r=.02, n s)$. The same was true for narcissism facets (L/A: $r=.05$, $n s, \mathrm{~S} / \mathrm{S}: r=-.08, n s, \mathrm{~S} / \mathrm{A}: r=-.03, n s, \mathrm{E} / \mathrm{E}: r=.06, n s)$. Although E/E seemed to be related to a more humorous verbal expression $(r=.21, p<$ $.05)$, and verbal humor was related to popularity in the audio-only condition $(r=.28, p<.05)$, this was not sufficient to make E/E narcissists more popular based on their voice only. For exploratory reasons, we also analyzed some additional verbal cues like number of words used, speech rate, tone of voice, calmness of voice, and loudness of voice. None of these cues were related to narcissism and its facets, with the exception that L/A narcissists had a somewhat calmer voice $(r=.21, p<.05)$. Again, although calmness of voice was perceived positively $(r=.34, p<.01)$, this did not make L/A narcissists more popular. Not surprisingly, given a further reduced amount of information, no effects of narcissism and its facets on popularity could be observed in an additional study using a "transcript only" condition $(N=60)$.
} 
Table 4

Narcissism as a Predictor of Popularity at First Sight (Study 2-4: Video-Based Judgments)

\begin{tabular}{lccc}
\hline & \multicolumn{3}{c}{ Popularity } \\
\cline { 2 - 4 } \multicolumn{1}{c}{ Predictor } & $\begin{array}{c}\text { Study 2: Full } \\
\text { information }\end{array}$ & $\begin{array}{c}\text { Study 3: No } \\
\text { sound }\end{array}$ & $\begin{array}{c}\text { Study 4: Still } \\
\text { photo of body }\end{array}$ \\
\hline Narcissism & $.22^{*}$ & .15 & .15 \\
Leadership/Authority subscale & .05 & .02 & -.01 \\
Self-absorption/Self-admiration subscale & .14 & .06 & .18 \\
Superiority/Arrogance subscale & .16 & .17 & .10 \\
Exploitativeness/Entitlement subscale & $.30^{* *}$ & $.23^{*}$ & $.20^{*}$ \\
\hline
\end{tabular}

like narcissists at first sight, although they accurately perceive their narcissism. Perhaps, at zero acquaintance, people accurately perceive those aspects of narcissism that also lead to popularity (e.g., the narcissists' charming expression) but do not detect or misjudge other aspects (e.g., the narcissists' low trustworthiness). Future research might analyze this interesting pattern of results using diverse situational contexts as well as different sets of targets.

Which facet of narcissism fosters popularity at first sight? It is of interest that the positive effect on popularity depended on the facet of narcissism under consideration. In contrast to the consistent specificity hypothesis and in line with the paradoxical specificity hypothesis, the most maladaptive facet of narcissism (E/E) was most strongly related to popularity at first sight. People with a sense of entitlement and a tendency to manipulate and exploit others were liked more at zero acquaintance. This was consistently shown for uninvolved and involved perceivers as well as for the different levels of information that the judgments were based on. Future research might additionally examine a broader array of interpersonal perceptions to analyze in more detail how narcissists are perceived by others.

What are the physical appearances and behavioral cues that mediate the effect of narcissism on popularity at first sight? According to our lens model approach, narcissists were expected to be popular at zero acquaintance because they should look and behave in ways that are immediately perceived as positive. These predictions were fully confirmed. Narcissism was related to fancier clothing, a more charming facial expression, more self-assured body movements, and more verbal humor, all of which led to popularity. For understanding the interpersonal consequences of narcissism, one has to consider and analyze the physical appearances and the nonverbal and verbal behaviors that are actually observable.

A lens model perspective can also be used to reconcile contradictory findings concerning the short-term interpersonal consequences of self-enhancement, a trait closely related to narcissism (e.g., John \& Robins, 1994). Paulhus (1998) reported that selfenhancement is related to positive peer impressions at short-term

Table 5

Observable Cues as Predictors of Popularity at First Sight (Study 2-4: Video-Based Judgments)

\begin{tabular}{|c|c|c|c|}
\hline \multirow[b]{2}{*}{ Cue } & \multicolumn{3}{|c|}{ Popularity } \\
\hline & $\begin{array}{l}\text { Study 2: Full } \\
\text { information }\end{array}$ & $\begin{array}{l}\text { Study 3: No } \\
\quad \text { sound }\end{array}$ & $\begin{array}{l}\text { Study 4: Still } \\
\text { photo of body }\end{array}$ \\
\hline Flashy and neat dress & $.33^{* *}$ & $.36^{* *}$ & $.38^{* * * *}$ \\
\hline Uncolored-colorful dress & $.29^{* *}$ & $.27^{*}$ & .18 \\
\hline Unfashionable-fashionable dress & $.21^{*}$ & $.24^{*}$ & $.33^{* *}$ \\
\hline Casual-chic dress & .16 & .15 & $.26^{*}$ \\
\hline Unstylish-stylish dress & $.20^{*}$ & $.29^{* * *}$ & $.33^{* * *}$ \\
\hline Unstylish-stylish hair & $.31^{* *}$ & $.32^{* * *}$ & $.25^{*}$ \\
\hline Charming facial expression & $.59^{* * * *}$ & $.58^{* * * * *}$ & \\
\hline Timid-self-assured facial expression & $.33^{* * *}$ & $.31^{* * *}$ & \\
\hline Grumpy-friendly facial expression & $.66^{* * * *}$ & $.67^{* * * *}$ & \\
\hline Self-assuredness of body movements & $.38^{* * * * *}$ & $.41^{* * * * *}$ & \\
\hline Stooped-straight posture & $.37^{* * * * *}$ & $.34^{* *}$ & \\
\hline Withdrawn-dominant behavior & .15 & .19 & \\
\hline Awkward-smooth body movement & $.39^{* * * *}$ & $.43^{* * * *}$ & \\
\hline Humorous verbal expression & $.35^{* *}$ & & \\
\hline Uses a salutation & .11 & & \\
\hline Conventional-original introduction & $.28^{* *}$ & & \\
\hline Serious-casual introduction & $.37^{* * * *}$ & & \\
\hline
\end{tabular}

Note. Target age and gender were partialed out of correlations for all cues. Narcissism-cue and cue-popularity correlations for aggregate cue measures are shown in boldface italics.

${ }^{*} p<.05 .{ }^{* * *} p<.01 .{ }^{* * * * *} p<.001$ (one-tailed). 
acquaintance. Other studies, however, found that the negative interpersonal consequences of self-enhancement are already apparent at short-term acquaintance, concluding that self-enhancers "manifest behaviors that are immediately detrimental to their social interactions" (Colvin et al., 1995, p. 1159).

According to our model, the popularity of self-enhancers depends on the cues they produce in the given social situation. Self-enhancers' popularity is thus dependent on situational constraints and affordances. When an interactive situation at shortterm acquaintance fosters more intense and controversial communication (e.g., a dyadic debate about the use of capital punishment with communication partners forced to argue for different positions; Colvin et al., 1995), the negative social habits of self-enhancers (e.g., disrupting others, hostility, and arrogance) are more easily observable and lead to more negative evaluations by others. In contrast, when the social situation is less intense and controversial (describing a family member's or friend's personality in a group meeting; Paulhus, 1998), the positive first impressions that self-enhancers evoke in others might hold for a longer time.

How much information is necessary to make narcissists popular at first sight? Across studies, a very consistent pattern of results could be revealed. Narcissists with a sense of entitlement and a tendency to exploit others (E/E facet) were more popular at first sight. This was true for highly involved perceivers in a real-life setting (Study 1) as well as for uninvolved perceivers exposed to the full information of the targets' behaviors (Study 2), the physical and nonverbal information (Study 3), or the physical information only (Study 4).

These findings parallel research on the accuracy of personality judgments based on thin slices of the targets' behaviors and physical appearances. In many cases, the accuracy of snap judgments only increases slightly when based on more information (Ambady \& Rosenthal, 1992; Ambady \& Skowronski, 2008; Kenny, 1994). Accurate personality judgments can result even when based solely on physical information (e.g., Borkenau \& Liebler, 1992). Specifically for narcissism, researchers have shown that observers are able to judge targets' narcissism on the basis of full-body photographs (Vazire et al., 2008).

\section{Short-Term Adaptiveness as a Reason for the Long-Term Maladaptiveness of Narcissism}

With regard to the interpersonal adaptiveness of narcissism, a puzzling finding was revealed. Not only was narcissism-a maladaptive interpersonal trait—related to popularity at first sight, but the most maladaptive facet, $\mathrm{E} / \mathrm{E}$, was most effective in impressing others. This paradoxical pattern is not only fascinating but also- as is true for many of the narcissism paradoxes-might have a functional meaning. We speculate that the positive social reactions that narcissists evoke in others at first sight might play an important role in maintaining their problematic interpersonal behavior and intrapersonal coping mechanisms that are dysfunctional in the long run. Strangers like narcissists at zero acquaintance and will thus immediately show more positive reactions toward them. In this manner, however, the negative interpersonal motivations and behavioral strategies of narcissists become reinforced, specifically the most problematic aspects.

Such reinforcing signs will quickly be perceived by narcissists as a confirmation of their superiority. Narcissists are generally "quick to perceive (or even impose) self-esteem implications in situations that leave room for it and then engage in characteristic social-cognitiveaffective dynamic self-regulatory strategies to maintain self-worth" (Morf \& Rhodewalt, 2001, p. 178). They generally overestimate their positive personality characteristics (Paulhus, 1998), their contribution to group performances (John \& Robins, 1994), their physical attractiveness (Gabriel, Critelli, \& Ee, 1994), and how physically attractive they are seen by others (Rhodewalt \& Eddings, 2002). But at zero acquaintance, the feeling of being admired must be an even stronger one because narcissists are indeed liked more, which should be reflected in their peers' immediate reactions.

The perception of being admired will amplify the narcissists' problematic intra- and interpersonal strategies. Moreover, it will strengthen their search for similar situations that will allow them to create the positive feedback they are seeking and depend on. Being admired by others is like a drug for narcissists. They "must continuously ask others whether they hold admiring opinions of the narcissists" (Morf \& Rhodewalt, 2001, p. 179). However, interpersonal relationships imply a development toward more intimate and cooperative communication. Cooperative orientations and behaviors are at odds with narcissists' typical intrapersonal processes and interpersonal strategies: They are not motivated and not used to cooperating with others. People only serve as an ego-booster for narcissists but do not have any value in their own right. Moreover, due to their higher impulsivity, narcissists behave less dependably and are less able to delay gratification (Vazire \& Funder, 2006). Narcissists also engage in status self-enhancement, which is related to being disruptive to group processes (Anderson et al., 2008). As time goes by, others recognize this pattern, which leads to the typical negative interpersonal reactions and a withdrawal of the admiration that the narcissists need. Narcissists, in turn, are not going to change their behavior toward these persons because of their dispositional impulsivity (Vazire \& Funder, 2006) and because they do not seek approval, but rather admiration (Raskin, Novacek, \& Hogan, 1991a). As a consequence, narcissists are continuously searching for new acquaintances who, as they have learned, will immediately admire them. This hinders them from establishing relationships or from sticking with social contexts in which they are embedded for a longer period of time (Robins \& Beer, 2001). In summary, we suggest that the positive interpersonal reactions narcissists evoke at zero acquaintance are an important part of the vicious interpersonal cycle that narcissists experience.

\section{Emmon's Paradoxes Reconsidered}

Twenty-five years ago, Robert Emmons (1984) pointed out four apparent paradoxes that he thought should be addressed in future research. These paradoxes are still important and prevailing topics in research on narcissism. We summarize and reconsider them against the background of our present research.

The first paradox Emmons (1984) mentioned refers to the difficulty of answering the adaptiveness question. In his words: "Where the distinction is between healthy and pathological narcissism is difficult to say" (p. 298). Research in the last two decades has shown that the general adaptiveness of narcissism depends on (a) the facet being considered (E/E narcissism being more maladaptive; Emmons, 1987; Raskin \& Novacek, 1989; Rhodewalt \& Morf, 1995) and (b) the particular situational affordances implied in short-term or long-term interpersonal relations 
(more negative interpersonal consequences in the long run; Paulhus, 1998). We were able to show that the specific combinations of facet and time point can have an additional value for predicting interpersonal consequences (E/E narcissists being more popular at zero acquaintance). Altogether, these findings suggest that both approaches - the consideration of facets as well as of situational circumstances that allow for the expression of personality - can be combined for a better understanding of the social consequences of narcissism.

Second, Emmons termed the most apparent contradiction of narcissists, devaluating others/not caring about others versus needing the admiration of others, the narcissistic paradox. This paradox has repeatedly been described in narcissism research. Kernberg (1975) speaks of "a curious apparent contradiction between a very inflated concept of themselves and an inordinate need for tribute from others" (p. 655). Other studies have confirmed this view: "Paradoxically, although narcissists feel contempt and distrust for others, they are dependent on positive social feedback" (Morf \& Rhodewalt, 1993). In turn, as narcissists "yearn and reach for self-affirmation, they destroy the very relationships on which they are dependent" (Morf \& Rhodewalt, 2001, p. 179). It is interesting to note that narcissists could "solve" this paradox by relying on positive feedback from unacquainted others whom they do not have to value. Because others truly like narcissists at first sight, they contribute to the maintenance of the narcissist's most paradoxical mindset. This also shows why getting-acquainted situations are so essential for narcissists, particularly for those with a sense of entitlement and a tendency to exploit others: These situations are needed so that the narcissist can be admired by others.

The third issue Emmons referred to were developmental determinants of narcissism, particularly the influence of parental social reactions on a child's narcissism. Emmons concluded that research should be directed toward a resolution of the devaluation (Kernberg, 1975; Kohut, 1977) versus overvaluation (Millon, 1981) theories of narcissistic development. A combination of both developmental factors, parental overvaluation and parental devaluation, has already been suggested by Freud (1914/1990) and was recently supported using quantitative analyses of childhood recollections (Otway \& Vignoles, 2006). The existence of both excessive but indiscriminate parental praise as well as continuous implicit parental messages of coldness and rejection, rather than warmth and acceptance, "may help to explain the paradoxical combination of grandiosity and fragility that is so characteristic of adult narcissists" (Otway \& Vignoles, 2006, p. 113).

Together with prior studies on the long-term interpersonal consequences of narcissism, the present results show that a similar pattern of social reactions applies to peers of adult narcissists: admiration for superficial reasons at zero acquaintance as well as rejection and a lack of warmth and acceptance later on. Research on the conditions and processes that are responsible for the maintenance of narcissists' problematic intra- and interpersonal processes could consider the importance of these peer reactions.

Fourth, Emmons identified the narcissist's lack of insight as a major issue to investigate. This topic is closely related to the former points. We speculate that the short-term positive feedback narcissists get from their peers might make them believe that they are behaving in an optimal way and might boost their ego. Consequently, they stick to their maladaptive interpersonal behavior and do not feel a need for self-criticism. Because of their ongoing selfishness, they do not get affective support in the long run, and they do not manage to develop intimate relationships. As a consequence, their self stays vulnerable, making immediate admiration even more necessary, and so forth. In research on as well as treatments of narcissists' self-insight, one should focus on both the intrapersonal mechanisms of narcissists and the social reactions that narcissists actually receive.

\section{Prospects for Future Research: Revealing the Developmental Course of Narcissists' Interpersonal Effects}

In summary, research shows that narcissists are popular at first sight (present studies), (sometimes) popular at short-term acquaintance (Paulhus, 1998), and unpopular in the long run (Colvin et al., 1995; Paulhus, 1998). This reversal of impressions on others is remarkable because it is at odds with the usually fairly high stability of early impressions (Ambady \& Skowronski, 2008; Funder, 1999; Kenny, 1994; Newcomb, 1961). Peers of narcissists indeed have to unlearn their positive initial impressions (Paulhus, 1998).

How does this happen? What remains unclear is why exactly narcissists become unpopular over time. In the Paulhus (1998) study, narcissists were unpopular after a 7-week period (about 2.5 hrs in contact). Different factors might explain this reversal of narcissists' impressions on others over time, for instance, discrepancies between their self-promotional claims and their actual behavior; the lack of sensitivity to feedback from their peers; or arrogant, hostile, self-absorbed, and defensive behaviors (Colvin et al., 1995; Morf \& Rhodewalt, 2001; Paulhus, 1998). However, none of these plausible explanations has been tested yet. What needs to be examined is the exact time course of narcissists' effects on others, the situational features that accelerate or decelerate the decline of narcissists' popularity, and, most importantly, the actual behaviors (Baumeister, Vohs, \& Funder, 2007) of narcissists that turn others off. A complete account of the development and the interpersonal consequences of narcissism research should, moreover, incorporate the social perceptions and behaviors of narcissists' social partners. A variety of research tools might help to realize such studies, including detailed behavioral observation and interaction analysis, continuous online attraction judgments, and ambulatory assessments of impressions and behaviors of narcissists and their social partners within a real-life context.

Such research can also help to specify present dynamic selfregulatory process models of narcissism (Morf \& Rhodewalt, 2001) with regard to the behaviors narcissists show (depending on the situation as well as on characteristics of the social partner), the social impressions these behaviors evoke (depending on the situation as well as characteristics of the social partners), and the behavioral reactions social partners of narcissists show.

\section{Conclusions}

In the present research, we showed that narcissists, particularly those with a sense of entitlement and a tendency to manipulate and exploit others, are popular at zero acquaintance. We moreover aimed to explain why this is the case: Our analyses suggest that narcissists are liked more at first sight because of their flashy and neat clothing, their charming facial expressions, their self-assured body movements, and their humorous verbal expressions. Of in- 
terest is that this pattern of results could be replicated when examining attraction judgments of uninvolved perceivers based on full information, nonverbal information, or even solely based on physical information. We hypothesized that the immediate popularity of narcissists might ironically be a major reason for their interpersonal problems in the long run-a perspective that seems worthy of follow-up in future studies. We hope that the result of such approaches will promote a deeper understanding of the fascinating paradoxes of narcissism.

\section{References}

Ambady, N., \& Rosenthal, R. (1992). Thin slices of expressive behavior as predictors of interpersonal consequences: A meta-analysis. Psychological Bulletin, 111, 256-274.

Ambady, N., \& Rosenthal, R. (1993). Half a minute: Predicting teacher evaluations from thin slices of nonverbal behavior and physical attractiveness. Journal of Personality and Social Psychology, 64, 431-441.

Ambady, N., \& Skowronski, J. (Eds.). (2008). First impressions. New York: Guilford Press.

American Psychiatric Association. (1994). Diagnostic and statistical manual of mental disorders (4th ed.). Washington, DC: Author.

Anderson, C., Ames, D. R., \& Gosling, S. D. (2008). Punishing hubris: The perils of overestimating one's status in a group. Personality and Social Psychology Bulletin, 34, 90-101.

Asendorpf, J. B. (1987). Videotape reconstructions of emotions and cognitions related to shyness. Journal of Personality and Social Psychology, $53,542-549$.

Asendorpf, J. B. (1988). Individual response profiles in the behavioral assessment of personality. European Journal of Personality, 2, 155-167.

Back, M. D., Schmukle, S. C., \& Egloff, B. (2008a). Becoming friends by chance. Psychological Science, 19, 439-440.

Back, M. D., Schmukle, S. C., \& Egloff, B. (2008b). A closer look at first sight: Social relations lens model analyses of personality and interpersonal attraction at zero acquaintance. Manuscript submitted for publication.

Back, M. D., Schmukle, S. C., \& Egloff, B. (2008c). How extraverted is honey.bunny77@hotmail.de? Inferring personality from e-mail addresses. Journal of Research in Personality, 42, 1116-1122.

Back, M. D., Schmukle, S. C., \& Egloff, B. (in press). Predicting actual behavior from the explicit and implicit self-concept of personality. Journal of Personality and Social Psychology.

Bar, M., Neta, M., \& Linz, H. (2006). Very first impressions. Emotion, 6, 269-278.

Baumeister, R. F., Vohs, K. D., \& Funder, D. C. (2007). Psychology as the science of self-reports and finger movements: Whatever happened to actual behavior? Perspectives on Psychological Science, 2, 396-403.

Berscheid, E., \& Reis, H. T. (1998). Attraction and close relationships. In D. T. Gilbert, S. T. Fiske, \& G. Lindzey (Eds.), The handbook of social psychology (4th ed., Vol. 2, pp. 193-281). New York: McGraw-Hill.

Bleske-Rechek, A., Remiker, M. W., \& Baker, J. P. (2008). Narcissistic men and women think they are so hot-But they are not. Personality and Individual Differences, 45, 420-424.

Bond, C. F., Jr., \& Lashley, B. R. (1996). Round-robin analyses of social interactions: Exact and estimated standard errors. Psychometrika, 61, 303-311.

Borkenau, P., \& Liebler, A. (1992). Trait inferences: Sources of validity at zero acquaintance. Journal of Personality and Social Psychology, 62, 645-657.

Borkenau, P., Mauer, N., Riemann, R., Spinath, F. M., \& Angleitner, A. (2004). Thin slices of behavior as cues of personality and intelligence. Journal of Personality and Social Psychology, 86, 599-614.

Brunswik, E. (1956). Perception and the representative design of experiments. Berkeley: University of California Press.
Cashdan, E. (1998). Smiles, speech, and body posture: How women and men display sociometric status and power. Journal of Nonverbal Behavior, 22, 209-228.

Colvin, C. R., Block, J., \& Funder, D. C. (1995). Overly positive evaluations and personality: Negative implications for mental health. Journal of Personality and Social Psychology, 68, 1152-1162.

DePaulo, B. M. (1992). Nonverbal behavior and self-presentation. Psychological Bulletin, 111, 203-243.

Draine, S. C. (2001). Inquisit (Version 1.32) [Computer software]. Seattle: Millisecond Software.

Duckworth, K. L., Bargh, J. A., Garcia, M., \& Chaiken, S. (2002). The automatic evaluation of novel stimuli. Psychological Science, 13, 513519.

Eagly, A. H., Ashmore, R. D., Makhijani, M. G., \& Longo, L. C. (1991). What is beautiful is good, but . ..: A meta-analytic review of research on the physical attractiveness stereotype. Psychological Bulletin, 110, 109128 .

Egloff, B., \& Schmukle, S. C. (2002). Predictive validity of an Implicit Association Test for assessing anxiety. Journal of Personality and Social Psychology, 83, 1441-1455.

Ellis, H. (1898). Auto-eroticism: A psychological study. Alienist and Neurologist, 19, 260-299.

Ellyson, S. L., \& Dovidio, J. F. (Eds.). (1985). Power, dominance, and nonverbal behavior. New York: Springer.

Emmons, R. A. (1984). Factor analysis and construct validity of the Narcissistic Personality Inventory. Journal of Personality Assessment, 48, 291-300.

Emmons, R. A. (1987). Narcissism: Theory and measurement. Journal of Personality and Social Psychology, 52, 11-17.

Emmons, R. A. (1989). Exploring the relations between motives and traits: The case of narcissism. In D. M. Buss \& N. Cantor (Eds.), Personality psychology: Recent trends and emerging directions (pp. 32-44). New York: Springer.

Feingold, A. (1992). Good-looking people are not what we think. Psychological Bulletin, 111, 304-341.

Freud, S. (1990). Zur Einführung des Narzissmus [On narcissism: An introduction]. In Gesammelte Werke (8 ed.). Frankfurt: S. Fischer. (Original published 1914)

Friedman, H. S., Riggio, R. E., \& Casella, D. F. (1988). Nonverbal skill, personal charisma, and initial attraction. Personality and Social Psychology Bulletin, 14, 203-211.

Funder, D. C. (1995). On the accuracy of personality judgment: A realistic approach. Psychological Review, 102, 652-670.

Funder, D. C. (1999). Personality judgment: A realistic approach to person perception. San Diego, CA: Academic Press.

Funder, D. C. (2001). The realistic accuracy model and Brunswik's approach to social judgment. In K. R. Hammond \& T. R. Stewart (Eds.), The essential Brunswik: Beginnings, explications, applications (pp. 365-369). New York: Oxford University Press.

Funder, D. C., Furr, R. M., \& Colvin, C. R. (2000). The Riverside Behavioral Q-sort: A tool for the description of social behavior. Journal of Personality, 68, 451-489.

Funder, D. C., \& Sneed, C. D. (1993). Behavioral manifestations of personality: An ecological approach to judgmental accuracy. Journal of Personality and Social Psychology, 64, 479-490.

Gabriel, M. T., Critelli, J. W., \& Ee, J. S. (1994). Narcissistic illusions in self-evaluations of intelligence and attractiveness. Journal of Personality, 62, 143-155.

Gosling, S. D., Ko, S. J., Mannarelli, T., \& Morris, M. E. (2002). A room with a cue: Personality judgments based on offices and bedrooms Journal of Personality and Social Psychology, 82, 379-398.

Harker, L. A., \& Keltner, D. (2001). Expressions of positive emotion in women's college yearbook pictures and their relationship to personality 
and life outcomes across adulthood. Journal of Personality and Social Psychology, 80, 112-124.

Jackson, L. A., Hunter, J. E., \& Hodge, C. N. (1995). Physical attractiveness and intellectual competence: A meta-analytic review. Social Psychology Quarterly, 58, 108-122.

John, O. P., \& Robins, R. W. (1994). Accuracy and bias in self-perception: Individual differences in self-enhancement and the role of narcissism. Journal of Personality and Social Psychology, 66, 206-219.

Keating, C. F., Mazur, A., Segall, M. H., Cysneiros, P. G., Divale, W. T., Kilbride, J. E., et al. (1981). Culture and the perception of social dominance from facial expression. Journal of Personality and Social Psychology, 40, 615-626.

Kenny, D. A. (1994). Interpersonal perception: A social relations analysis. New York: Guilford Press.

Kenny, D. A., Kashy, D. A., \& Cook, W. L. (2006). Dyadic data analysis. New York: Guilford Press.

Kernberg, O. (1975). Borderline conditions and pathological narcissism. New York: Aronson.

Kernberg, O. (1980). Internal world and external reality. New York: Aronson.

Kohut, H. (1977). The restoration of the self. New York: International Universities Press.

Kwan, V. S. Y., John, O. P., Robins, R. W., \& Kuang, L. L. (2008). Conceptualizing and assessing self-enhancement bias: A componential approach. Journal of Personality and Social Psychology, 94, 10621077.

Langlois, J. H., Kalakanis, L., Rubenstein, A. J., Larson, A., Hallam, M., \& Smoot, M. (2000). Maxims or myths of beauty? A meta-analytic and theoretical review. Psychological Bulletin, 126, 390-423.

Levesque, M. J., \& Kenny, D. A. (1993). Accuracy of behavioral predictions at zero acquaintance: A social relations analysis. Journal of Personality and Social Psychology, 65, 1178-1187.

Mehl, M. R., Gosling, S. D., \& Pennebaker, J. W. (2006). Personality in its natural habitat: Manifestations and implicit folk theories of personality in daily life. Journal of Personality and Social Psychology, 90, 862877

Millon, T. (1981). Disorders of personality. New York: Wiley.

Morf, C. C., \& Rhodewalt, F. (1993). Narcissism and self-evaluation maintenance: Explorations in object relations. Personality and Social Psychology Bulletin, 19, 668-676.

Morf, C. C., \& Rhodewalt, F. (2001). Unraveling the paradoxes of narcissism: A dynamic self-regulatory processing model. Psychological Inquiry, 12, 177-196.

Murphy, N. A. (2007). Appearing smart: The impression management of intelligence, person perception accuracy, and behavior in social interaction. Personality and Social Psychology Bulletin, 33, 325-339.

Muthén, L. K., \& Muthén, B. O. (2006). Mplus: User's guide (4th ed.). [Software manual]. Los Angeles: Author.

Newcomb, T. M. (1961). The acquaintance process. New York: Holt, Rinehart, \& Winston.

Oltmanns, T. F., Friedman, J. N. W., Fiedler, E. R., \& Turkheimer, E. (2004). Perceptions of people with personality disorders based on thin slices of behavior. Journal of Research in Personality, 38, 216-229.

Otway, L. J., \& Vignoles, V. L. (2006). Narcissism and childhood recollections: A quantitative test of psychoanalytic predictions. Personality and Social Psychology Bulletin, 32, 104-116.

Paulhus, D. L. (1998). Interpersonal and intrapsychic adaptiveness of trait self-enhancement: A mixed blessing. Journal of Personality and Social Psychology, 74, 1197-1208.

Raskin, R., \& Hall, C. S. (1979). A narcissistic personality inventory. Psychological Reports, 45, 590.

Raskin, R., \& Novacek, J. (1989). An MMPI description of the narcisstic personality. Journal of Personality Assessment, 53, 66-80.
Raskin, R., Novacek, J., \& Hogan, R. (1991a). Narcissism, self-esteem, and defensive self-enhancement. Journal of Personality, 59, 19-38.

Raskin, R., Novacek, J., \& Hogan, R. (1991b). Narcissistic self-esteem management. Journal of Personality and Social Psychology, 60, 911918.

Raskin, R., \& Terry, H. (1988). A principle-components analysis of the Narcissistic Personality Inventory and further evidence of its construct validity. Journal of Personality and Social Psychology, 54, 890-902.

Reis, H. T., Wilson, I. M., Monestere, C., Bernstein, S., Clark, K., Seidl, E., et al. (1990). What is smiling is beautiful and good. European Journal of Social Psychology, 20, 259-267.

Rhodewalt, F., \& Eddings, S. (2002). Narcissus reflects: Memory distortion in response to ego-relevant feedback in high- and low-narcisstic men. Journal of Research in Personality, 36, 97-116.

Rhodewalt, F., \& Morf, C. C. (1995). Self and interpersonal correlates of the Narcissistic Personality Inventory: A review and new findings. Journal of Research in Personality, 29, 1-23.

Robins, R. W., \& Beer, J. S. (2001). Positive illusions about the self: Short-term benefits and long-term costs. Journal of Personality and Social Psychology, 80, 340-352.

Schütz, A., Marcus, B., \& Sellin, I. (2004). Die Messung von Narzissmus als Persönlichkeitskonstrukt: Psychometrische Eigenschaften einer Lang- und einer Kurzform des deutschen NPI. [Measuring narcissism as a personality construct: Psychometric properties of a long and a short version of the German Narcissistic Personality Inventory]. Diagnostica, $50,202-218$.

Shrout, P. E., \& Fiske, D. W. (1981). Nonverbal behavior and social evaluation. Journal of Personality, 49, 115-128.

Taylor, S. E., \& Brown, J. D. (1988). Illusion and well-being: A social psychological perspective on mental health. Psychological Bulletin, 103, 193-210.

Taylor, S. E., \& Brown, J. D. (1994). Positive illusions and well-being revisited: Separating fact from fiction. Psychological Bulletin, 116, 21-27.

Taylor, S. E., Lerner, J. S., Sherman, D. K., Sage, R. M., \& McDowell, N. K. (2003). Portrait of the self-enhancer: Well adjusted and well liked or maladjusted and friendless. Journal of Personality and Social Psychology, 84, 165-176.

Taylor, S. E., Wayment, H. A., \& Collins, R. L. (1993). Positive illusions and affect regulation. In D. M. Wegner \& J. W. Pennebaker (Eds.), Handbook of mental control (pp. 325-343). Englewood Cliffs, NJ: Prentice Hall.

Tice, D. M., Butler, J. L., Muraven, M. B., \& Stillwell, A. M. (1995). When modesty prevails: Differential favorability of self-presentation to friends and strangers. Journal of Personality and Social Psychology, 69, 1120 1138.

Vazire, S., \& Funder, D. C. (2006). Impulsivity and the self-defeating behavior of narcissists. Personality and Social Psychology Review, 10, $154-165$.

Vazire, S., Naumann, L. P., Rentfrow, P. J., \& Gosling, S. D. (2008). Portrait of a narcissist: Manifestations of narcissism in physical appearance. Journal of Research in Personality, 42, 1439-1447.

Wallace, H. M., \& Baumeister, R. F. (2002). The performance of narcissists rises and falls with perceived opportunity for glory. Journal of Personality and Social Psychology, 82, 819-834.

Watson, P. J., Grisham, S. O., Trotter, M. V., \& Biderman, M. D. (1984). Narcissism and empathy: Validity evidence for the Narcissistic Personality Inventory. Journal of Personality Assessment, 48, 301-305.

Young, S. M., \& Pinsky, D. (2006). Narcissism and celebrity. Journal of Research in Personality, 40, 463-471.

Received February 2, 2009

Revision received April 17, 2009

Accepted April 20, 2009 